http://jmscr.igmpublication.org/home/

ISSN (e)-2347-176x ISSN (p) 2455-0450

crossref DOI: https://dx.doi.org/10.18535/jmscr/v8i5.55

Journal Of Medical Science And Clinical Research

IGM Publication

An official Publication of IGM Publication

\title{
Rhinosporidiosis- It's Variable Presentations - A Case Series
}

\author{
Authors \\ Dr Ruta Shanmugam", Dr Viveknarayan.G ${ }^{2}$, Dr Balaji Swaminathan ${ }^{3}$, \\ Dr V.U. Shanmugam ${ }^{4}$, Dr Prem Nivas ${ }^{5}$ \\ ${ }^{1}$ Professor, Dept of ENT, RMMCH, Annamalai University, Chidambaram \\ ${ }^{2}$ Postgraduate, Dept of ENT, RMMCH, Annamalai University, Chidambaram \\ ${ }^{3} \mathrm{HOD}$, Dept of ENT, RMMCH, Annamalai University, Chidambaram \\ ${ }^{4}$ Professor, Dept of ENT, RMMCH, Annamalai University, Chidambaram \\ ${ }^{5}$ Assistant Professor, Dept of ENT, RMMCH, Annamalai University, Chidambaram
}

\begin{abstract}
Rhinosporidiosis is a disease endemic in India and srilanka. It usually affects the nasal mucosa and has a typical gross appearance in this study we are going to discuss a series of five cases of rhinosporidiosis with variable presentations.

Keywords: Rhinosporidiosis, Nasal muosa, Variable presentations.
\end{abstract}

\section{Introduction}

Rhinosporidiosis is a chronic, granulomatous disease caused by rhinosporidium seeberi ${ }^{2}$. Rhinosporidiosis is characterized by reddish polypoidal mass which are hyperplastic and friable ${ }^{2}$.It usually affects nasal mucosa but it can also involve nasopharynx, lips, palate, conjunctiva, larynx, trachea, penis, vagina, bones etc $^{1}$.,

\section{Case 1}

- A 20 year old male belonging to low socio economic status presented to our ENT opd with complaints of

- Mass in the oral cavity - 2 years.

- Difficulty in swallowing- 1 month.

- Bleeding from right side of nose on and off - 1month.

- Right sided nasal obstruction - 1month.

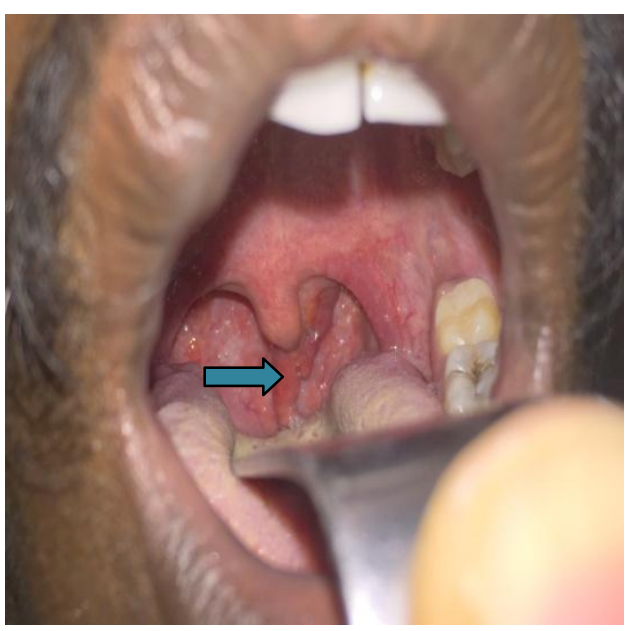

Examination of oropharynx revealed a single smooth reddish polypoidal mass hanging behind the uvula. Diagnostic nasal endosopy was done which revealed a single polypoidal mass arising from the soft palate and two separate polypoidal masses were seen arising from lateral wall of right nasal cavity. CECT of paranasal sinus revealed an enhancing soft tissue mass was seen arising from 


\section{JMSCR Vol||08||Issue||05||Page 292-296||May}

the soft palate extending upto the nasopharynx and oropharynx. Rhinosporidiosis usually arises from the nasal cavity mucosa in this patient it was seen arising from the soft palate and the typical gross appearance of rhinosporidiosis also was not present.

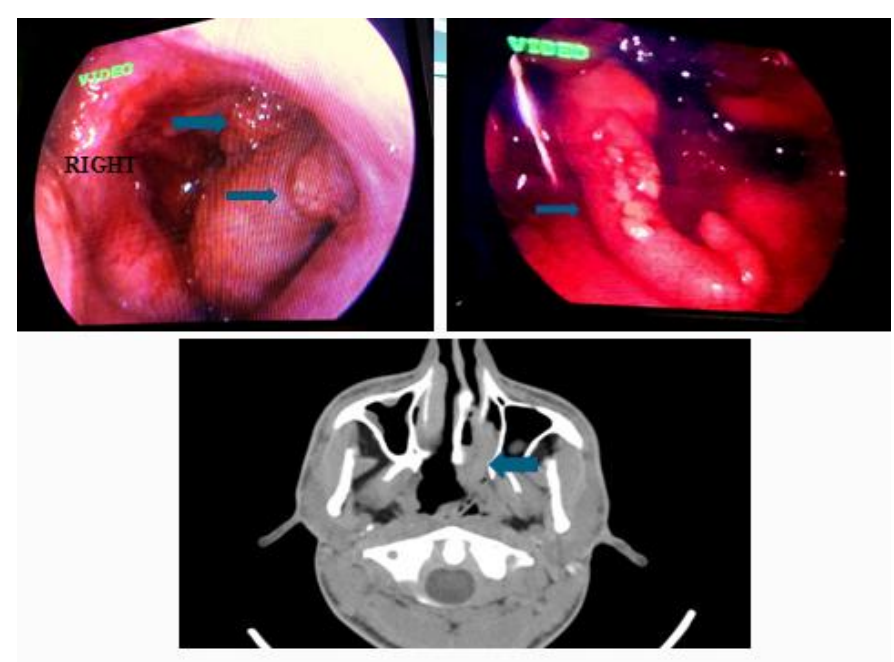

\section{Case 2}

- A 75 year old male agricultural worker came to our ENT opd with complaints of a prolapsing mass from the left nasal cavity for 1year.

- H/O of left sided nasal obstruction present.

- $\mathrm{H} / \mathrm{O}$ occasional bleeding from left side of nose present.

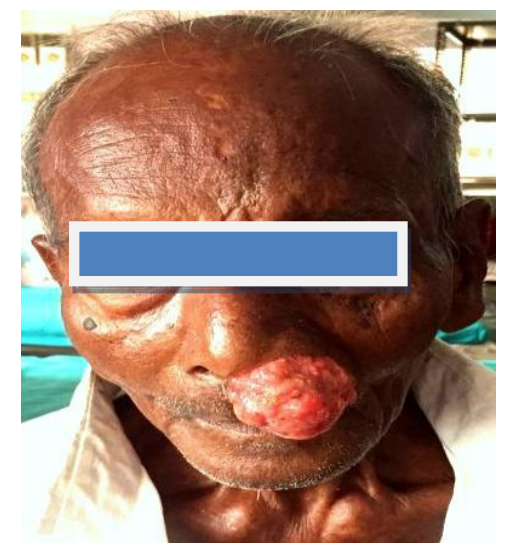

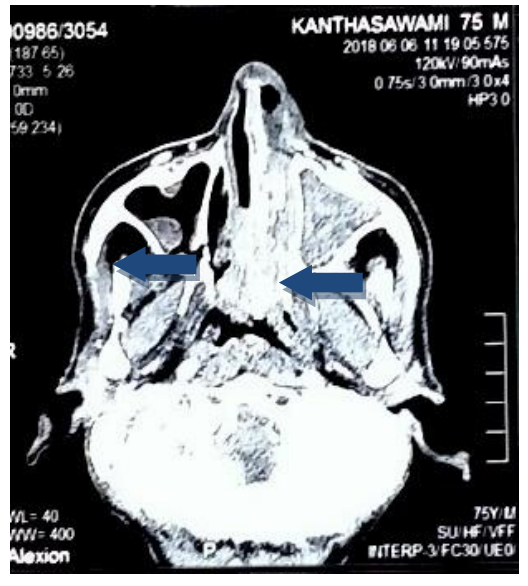

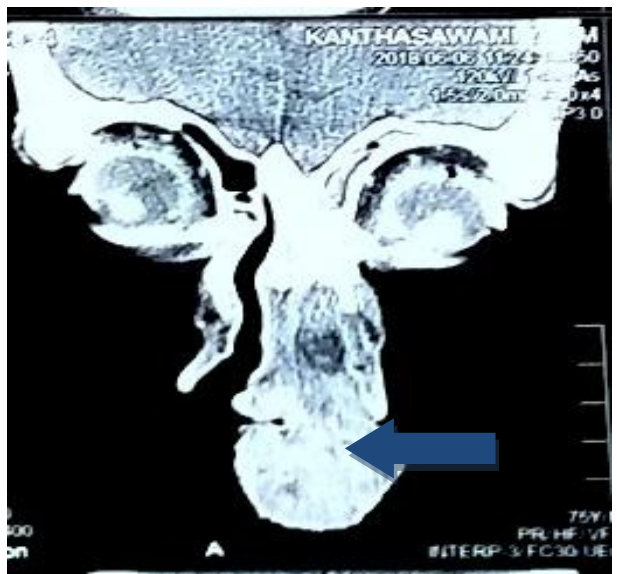

On examination a single fleshy polypoidal mass with irregular surface was seen protruding from the left nasal cavity which was bleeding on touch. With the age of the patient in a higher side our first differenential diagnosis was malignancy so an biopsy was done which revealed it as rhinosporidiosis. The usual age of presentation in rhinosporidiosis is $10-40 \mathrm{yrs}$ of age which was not applicable in this patient. The typical gross appearance of rhinosporidiosis also was not present in this patient.

\section{Case 3}

- A 45 year old male patient a hospital worker came with complaints of left sided nasal obstruction for 10 years.

- $\mathrm{H} / \mathrm{O}$ headache present

- H/O left sided nasal discharge present

- H/o nasal surgery done thrice before 20 years for similar complaints 

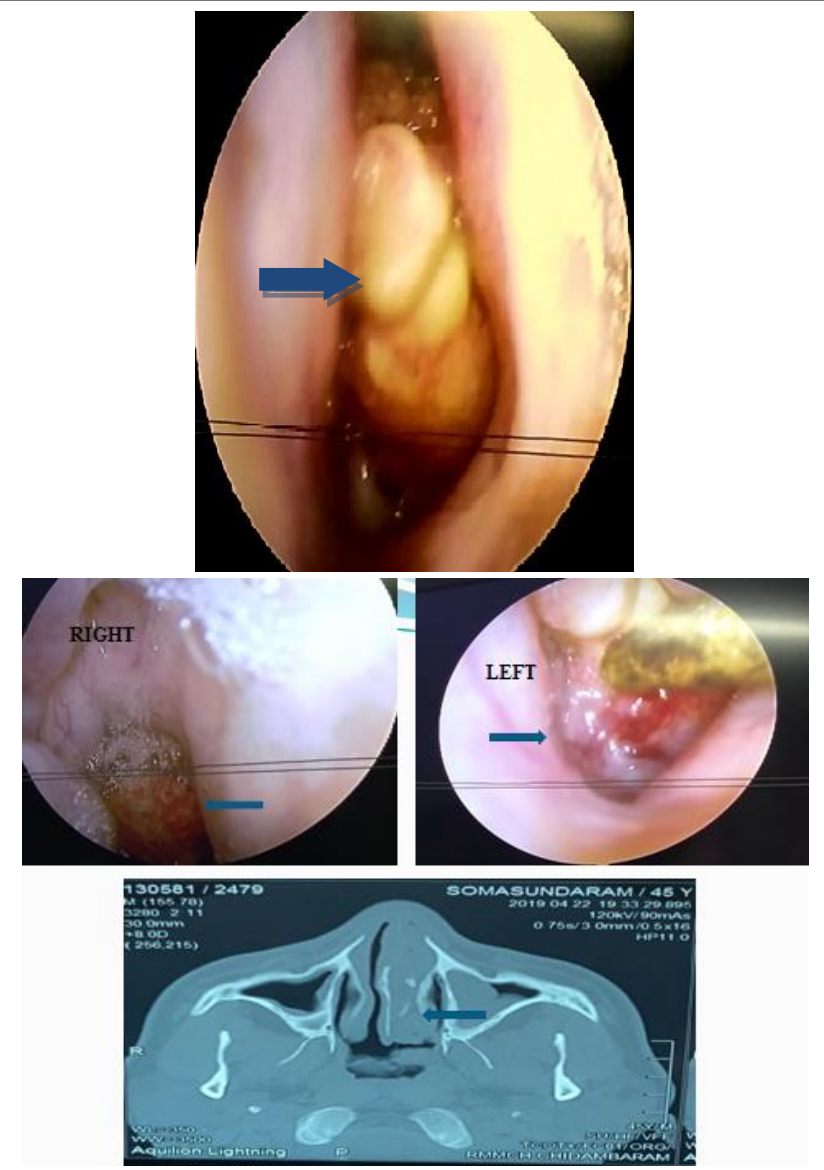

On diagnostic nasal endosopy a polypoidal mass was seen arising from the floor of the left nasal cavity which was bleeding on touch and in the right side a separate mass was seen arising from the nasopharynx. Nasopharynx is not the most common site of rhinosporidiosis. It usually arises from the nasal cavity mucosa.

\section{Case 4}

- A 27 year old house wife belonging to low socioeconomic status came to our opd with complaints of a prolapsed nasal mass from the left side of nasal cavity following an episode of sneezing.

- No symptoms previously.

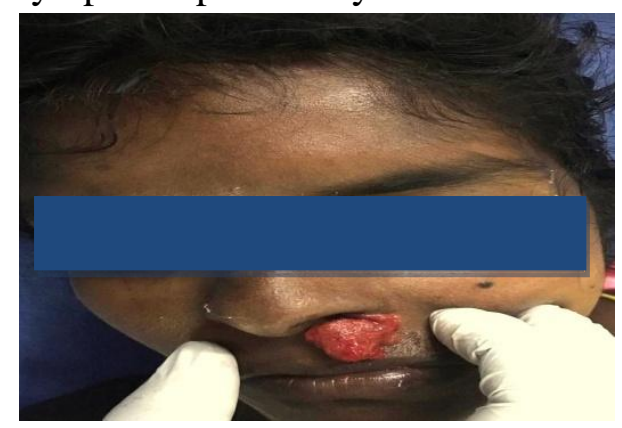

The typical gross appearance of rhinosporidiosis was present but the patient did not had any symptoms of rhinosporidiosis which was a variable presentation.

\section{Case 5}

- A 20 year old female, college student belonging to low socio economic status came to our opd with complaints of left sided nasal obstruction -1 month

- H/o bleeding from left side of nose.

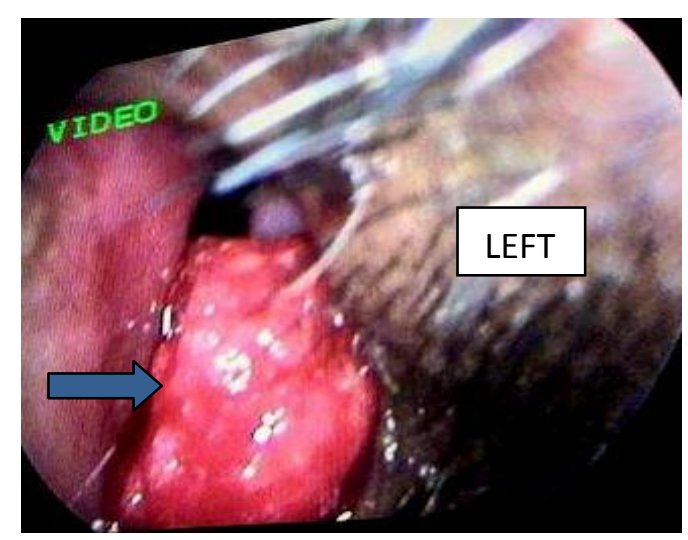

This patient had the symptoms with typical gross appearance of rhinosporidiosis but the history of bathing in ponds was not present in this patient which was present in all the other patients.

\section{Excision of the Mass with Cauterization of the} Base Was Done in all the above Mentioned Patients
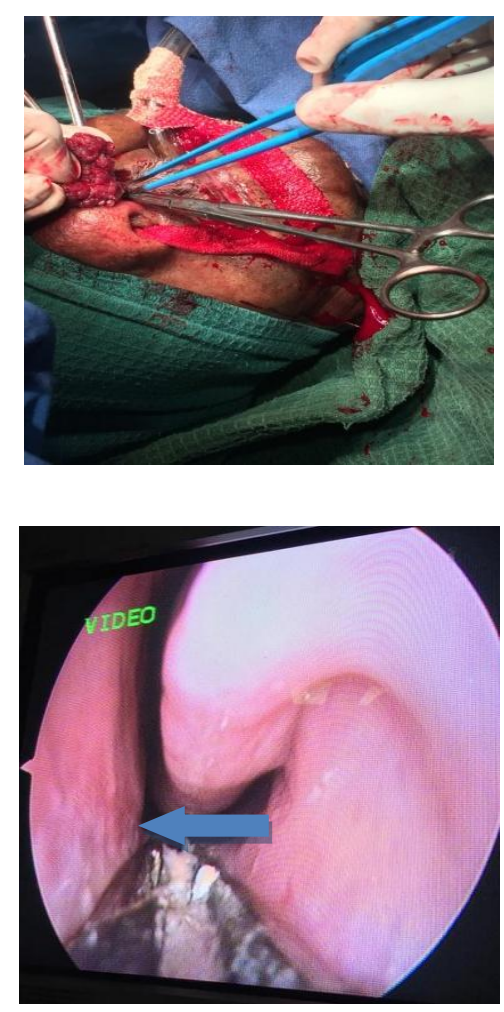


\section{JMSCR Vol||08||Issue||05||Page 292-296||May}
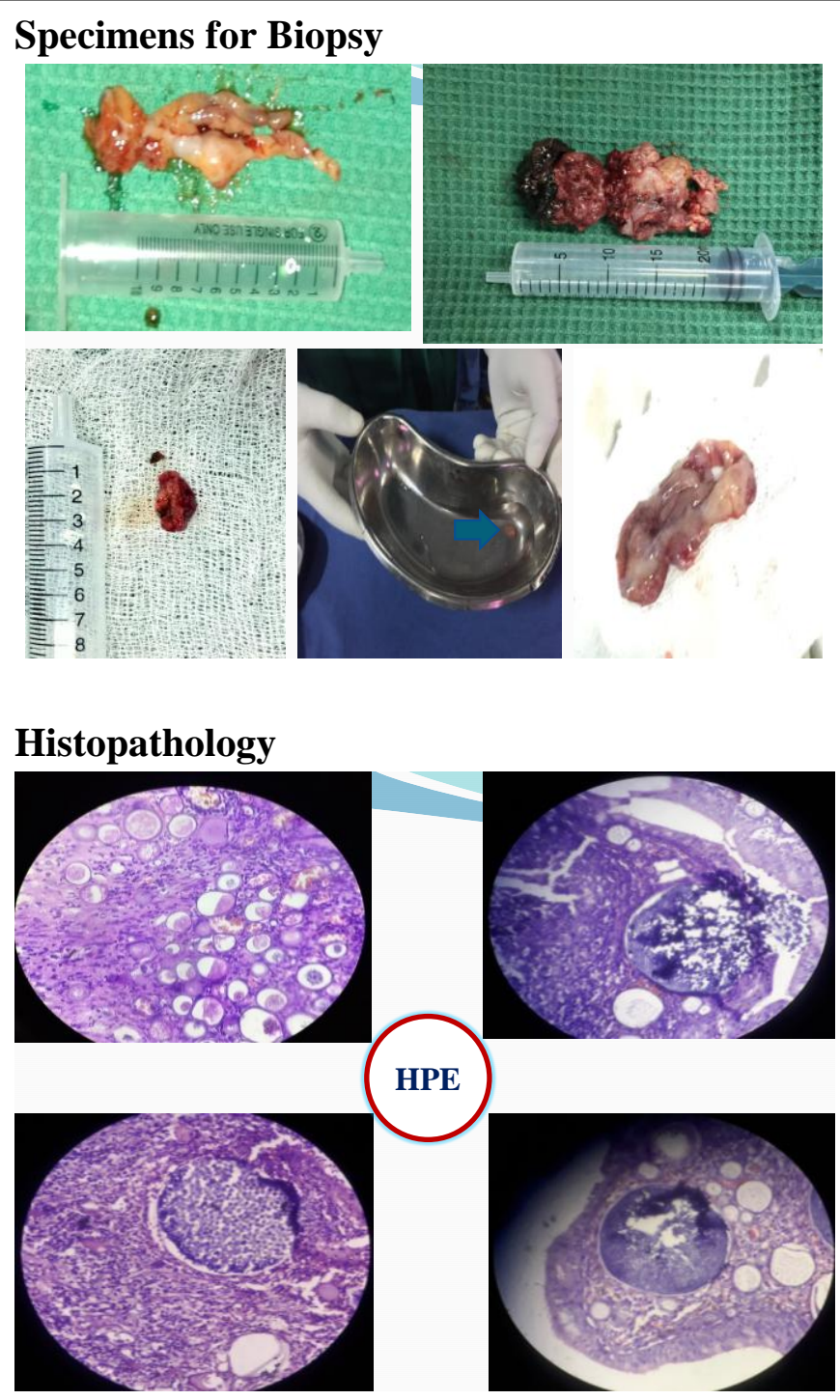

All the specimens had the features of rhinosporidiosis in HPE.

\section{Post Operative Period}

- Post operatively the patients were followed for about 6 months.

- Patients were started on T.DAPSONE $100 \mathrm{mg}$ once daily for six months.

- There was no recurrence.

\section{Discussion}

- Rhinosporidiosis is a chronic inflammatory disease common in India and srilanka ${ }^{1}$.

- It is caused by rhinosporidium seeberi ${ }^{2}$.

- The first case was reported by Malbran in 1892 and was published by seeber in $1900^{1}$.

- The mode of infection is usually through trans epithelial infection most commonly in nasal sites ${ }^{2}$.

- The definitive diagnosis is by histopathological examination ${ }^{4}$.

- Treatment - Surgical excision combined with electrocoagulation ${ }^{3}$.

\begin{tabular}{|l|l|}
\hline FEATURE & CLASSICAL \\
\hline SEX & $\begin{array}{l}\text { Four times more common in } \\
\text { males. }\end{array}$ \\
\hline AGE & $10-40$ years. \\
\hline $\begin{array}{l}\text { SOCIO ECONOMIC } \\
\text { STATUS }\end{array}$ & Low socio economic status. \\
\hline SYMPTOMS & $\begin{array}{l}\text { Nasal mass, obstruction, } \\
\text { epistaxis. (it may vary } \\
\text { according to site of infection) }\end{array}$ \\
\hline $\begin{array}{l}\text { GROSS } \\
\text { APPEARANCE }\end{array}$ & $\begin{array}{l}\text { Fleshy, vascular, polypoidal } \\
\text { mass, studded with white dots } \\
\text { on the surface. }\end{array}$ \\
\hline $\begin{array}{l}\text { ANATOMICAL } \\
\text { DISTRIBUTION }\end{array}$ & $\begin{array}{l}\text { Usually affects nasal mucous } \\
\text { membrane(can also involve } \\
\text { oropharynx,nasopharynx,eyes, } \\
\text { bones, etc..) }\end{array}$ \\
\hline
\end{tabular}

\section{IN MY CASE SERIES}

$3 / 5$ are males.(male predominance)

One patient age is 75 .

All patients belong to low socio economic status.

No symptom, Difficulty in swallowing, headache.

2/5 patients did not have the typical gross appearance

\section{Oropharynx , nasopharynx}




\section{Conclusion}

Rhinosporidiosis is a condition which both clinicians and pathologists should keep in mind when managing patients from endemic areas with nasal masses even though the gross appearance, symptoms and history is not typical.

\section{References}

1. Atypical presentations of rhinosporidiosis: a clinical dilemma? - jayanta saha . Asim jiban basu. Indranil sen. Ramanuj sinha. Achintya kr bhandari. Satadal mondal

2. Rhinosporidiosis: its varied pesentations v.p venkatachalam .nitin anand. Omender bhooshan.

3. Rhinosporidiosis - unusual presentations. Anirban ghosh . Somnath saha . Abhishek srivastava . Saibal mishra.

4. Rhinosporidiosis: Intraoperative cytological diagnosis in an unsuspected lesion. 